\section{Representaciones \\ metafóricas sobre el \\ docente en ejercicio \\ $y$ en formación. \\ Un estudio comparativo \\ de resultados obtenidos \\ en Chile y Argentina*}

Segundo semestre de 2019 - pp. 3-21

Segunda época

N. ${ }^{0}$
Metaphoric

Representations of

the In-service and

Pre-service Teacher.

A Comparative Study

of the Results in

Chile and Argentina

\author{
Representações \\ metafóricas sobre \\ o docente em \\ exercício e em \\ formação. \\ Um estudo \\ comparativo de \\ resultados obtidos \\ no Chile e na \\ Argentina
}

Paola Alarcón Hernández ${ }^{* *}$ Orcid: https://orcid.org/0000-0001-7217-5668

Patricia C. Hernández ${ }^{* * *}$ Orcid: https://orcid.org/0000-0002-2430-8611

* Esta investigación fue patrocinada por el Fondo Nacional de Desarrollo Científico y Tecnológico del Gobierno de Chile para el proyecto Fondecyt de iniciación n. ${ }^{\circ}$ 11130482: La metáfora conceptual como herramienta de análisis de creencias docentes en profesores de establecimientos educacionales de la comuna de Concepción (2013-2016).

** Universidad de Concepción. Correo electrónico: palarco@udec.cl

*** Instituto de Lingüística, Universidad de Buenos Aires; Laboratoire LLL, Université d'Orléans; Laboratoire DyLis, Université de Rouen Correo electrónico: patricia.c.hernandez.gr@gmail.com

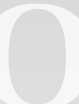
(1) 


\section{Resumen}

En este estudio de carácter cualitativo la metáfora conceptual constituye el marco teórico y a la vez metodológico para analizar las representaciones sobre el profesor y sobre un grupo de estudiantes de profesorado de la Ciudad Autónoma de Buenos Aires. El artículo retoma las conclusiones de una investigación similar (Alarcón, 2015) realizada con estudiantes de pedagogía de una universidad chilena. Para la obtención de metáforas, se adaptó el cuestionario aplicado en la universidad mencionada y se aplicó el mismo procedimiento. Para el análisis de las metáforas así obtenidas se tomaron como referencia las categorías propuestas por Saban (2004) y Alarcón (2015), esto es, metáforas conceptuales (i) centradas en la enseñanza, (ii) centradas en el aprendizaje, (iii) vinculadas a la valoración social del profesor y (iv) representativas del estudiante de pedagogía. El análisis cualitativo de los resultados permitió no solo caracterizar las metáforas conceptuales que subyacen en la concepción de los informantes argentinos sino también visibilizar las convergencias y divergencias de las respuestas obtenidas con las de los estudiantes chilenos.

\section{Palabras clave}

metáfora conceptual; estudiantes de pedagogía; análisis cualitativo

\section{Abstract}

In this qualitative study, conceptual metaphor is the theoretical and methodological framework used to analyze the representations of the in-service teachers and a group of pre-service teachers from the city of Buenos Aires. The paper summarizes the conclusions of a similar study (Alarcón, 2015) on pre-service teachers from a Chilean university. In order to collect metaphors, the questionnaire used in the study mentioned above was adapted and the same procedure was used. In order to analyze the metaphors thus obtained, the categories suggested by Saban (2004) and Alarcón (2015) were taken into consideration, i.e. conceptual metaphors (i) centered on teaching, (ii) centered on learning, (iii) linked to the social value of the teacher, and (iv) representative of the pre-service teacher. The qualitative analysis of the results allowed not only to characterize the conceptual metaphors underlying the Argentinean respondents conception, but also to make visible the convergence and divergence between the responses obtained and those provided by Chilean students.

\section{Keywords}

conceptual metaphor; pre-service teachers; qualitative analysis

\section{Resumo}

Neste estudo de caráter qualitativo a metáfora conceitual constitui o marco teórico e ao mesmo tempo metodológico para analisar as representações metafóricas sobre o professor e sobre um grupo de estudante de pedagogia da Ciudad Autónoma de Buenos Aires. 0 artigo retoma as conclusões de uma investigação semelhante (Alarcón, 2015) realizada com estudantes de pedagogia de uma universidade chilena. Para obter as metáforas, o questionário aplicado na universidade chilena foi adaptado, mantendo-se o mesmo procedimento. Para a análise das metáforas assim obtidas tomaram-se como referência as categorías propostas por Saban (2004) e Alarcón (2015), ou seja, metáforas conceituais (i) enfocadas no ensino (ii), enfocadas na aprendizagem (iii), vinculadas à valoração social do professor e (iv) representativas do estudante de pedagogia. A análise qualitativa dos resultados permitiu não só caracterizar as metáforas conceituais subjacentes à concepção dos informantes argentinos, como também tornar visível as convergências e divergências das respostas obtidas com as dos estudantes chilenos.

\section{Palavras-chave}

metáfora conceitual; estudantes de pedagogia; análise qualitativa 


\section{Introducción}

Este artículo retoma las conclusiones de Alarcón (2015) a propósito de las representaciones metafóricas tanto del profesor como de estudiantes de pedagogía que surgen del cuestionario aplicado a estudiantes de primer año de la carrera de Pedagogía en Español y de Pedagogía en Inglés de una universidad chilena ${ }^{1}$ en 2012 y 2013 . Tomando la metáfora conceptual como herramienta de análisis cualitativo, Alarcón (2015) identifica las creencias de los estudiantes que inician su trayecto formativo docente. Para ello, de acuerdo con las categorías propuestas por Saban (2004), se analizan las metáforas conceptuales (i) centradas en el profesor y orientadas a la enseñanza, (ii) relacionadas con el aprendizaje, (iii) vinculadas a la valoración social del profesor y (iv) representativas del estudiante de pedagogía.

Con el objeto de detectar la posible existencia de afinidades y recurrencias en las metaforizaciones propuestas por los profesores en formación, en noviembre de 2015 se aplicó un cuestionario similar a estudiantes argentinos de los Profesorados en alemán, francés y portugués del Instituto de Enseñanza Superior en Lenguas Vivas "Juan R. Fernández" de la Ciudad Autónoma de Buenos Aires, Argentina.

Tal estudio se inserta en el contexto de un intenso debate: la educación ocupa un lugar relevante en el discurso público y, a ambos lados de la cordillera, se produce una profunda reflexión, en ocasiones altamente crítica, sobre la formación, el desempeño docente y sus condiciones de trabajo. Vale decir que quienes optan por la carrera docente lo hacen en un entorno complejo atravesado por múltiples tensiones: el discurso de los estudiantes deviene así la caja de resonancia de un debate social.

En estas páginas, presentamos el marco teórico de nuestro trabajo (apartado 1), la metodología adoptada (apartado 2) y el análisis de los resultados obtenidos (apartados 3 y 4 ). Finalmente, brindamos las primeras conclusiones de este estudio.

1 El término Pedagogía en Inglés es la denominación vigente en Chile. Para estudios equivalentes, el término empleado en Argentina es Profesorado en Inglés. Emplearemos, según los casos, la denominación vigente en cada ámbito de estudio.

\section{La metáfora conceptual y el estudio del rol docente}

Tradicionalmente, la metáfora había sido considerada como una figura literaria, usada con propósitos poéticos o retóricos. Esta perspectiva fue desafiada por Lakoff y Johnson en el libro Metáforas de la vida cotidiana (1980) en el que propusieron que la metáfora es un proceso inevitable del razonamiento, usada sin mayor esfuerzo en la vida diaria de la gente común. Aunque la visión tradicional sigue vigente, se ve desmentida por la creciente evidencia de que es un fenómeno conceptual en lugar de ser exclusivamente lingüístico o estético (Kövecses, 2010; Sullivan, 2017).

La metáfora conceptual supone un conjunto sistemático de correspondencias resultante de la proyección de elementos, propiedades y relaciones de un dominio fuente (más relacionado con la experiencia corporal y social) a un dominio meta más abstracto (Lakoff y Johnson, 1980; Kövecses, 2010). Tales correspondencias producen una lógica particular para cada metáfora conceptual, mediante la cual se razona sobre determinados ámbitos de la realidad, razonamiento que se transparenta en una multiplicidad de expresiones.

Así, la metáfora proporciona una visión particular del tema en cuestión; destaca las similitudes entre los dos dominios y deja en el trasfondo aquellos aspectos irrelevantes para la comparación. Asimismo, facilita algunas inferencias mientras hace otras más improbables (Semino et al., 2018, p. 29). Este mecanismo permite a las personas expresar la manera en que comprenden sus experiencias. Su poder radica en que es un complejo de significados que incluye emociones, actitudes y valoraciones sobre el dominio meta.

La idea de que existen metáforas "mediante las que vivimos", como reza el título original del ensayo fundador de Lakoff y Johnson (Metaphors We Live $B y)$, ha sido y sigue siendo profundamente inspiradora para la investigación en ámbitos particulares de la experiencia humana y social, como lo prueban, para el caso de la enseñanza y el aprendizaje, títulos tales como Metaphors We Teach and Live By (Block, 
1992), Metaphors We Teach By. How Metaphors Shape What We Do in Classrooms (Bradley y Van Brummelen, 2012) o Metaphors We Learn By (Dalton, 2015).

En el ámbito de los docentes, el rol heurístico de la metáfora es crucial para descubrir los modelos cognitivos que permean la vida en el aula. ${ }^{2}$ Tal modelización se transparenta en el lenguaje: el lenguaje utilizado por los profesores para verbalizar su actividad profesional no suele ser literal, sino más bien simbólico y metafórico (Mellado et al., 2014, p. 156). Además, tal como lo señalan estos autores, las metáforas que construyen los docentes "dan una visión holística de la vida del aula y son un medio para articular el pensamiento y para establecer puentes entre las concepciones, el conocimiento práctico y la narrativa que describe la vida del aula" (Mellado et al., 2014, p. 156). Así lo confirman Mellado et al. (2016), para quienes la metáfora estimula la reflexión en los profesores sobre sus concepciones, roles y práctica docente. Así, según ellos "las metáforas tienen un fuerte componente afectivo y pueden ayudar a los profesores a tomar conciencia de sus sentimientos y emociones" (2016, p. 24). La investigación de estas metáforas conceptuales constituye por lo tanto un eficaz instrumento de conocimiento que permite averiguar los referentes implícitos que sustentan las concepciones, así como los modelos docentes en el aula (Dávila et al., 2017, p. 274). Más aún, para estos autores, las metáforas estructuran las creencias de los profesores y tienen un claro impacto sobre su conducta en el aula. ${ }^{3}$ Como lo afirman Wan y Low (2015), una reflexión sobre las metáforas en el contexto educativo permite incluso modificar la enseñanza y el aprendizaje. Así, las metáforas ayudan a los docentes a articular y construir representaciones de sí mismos y de su experiencia (Kramsch, 2003) y promover su con-

2 Estos Modelos Cognitivos Idealizados (Lakoff, 1987) que organizan nuestro conocimiento son complejos estructurados gestálticamente que pueden obedecer a principios diversos entre los cuales figuran las correspondencias metafóricas (1987, pp. 68, 113, 154).

3 Las creencias docentes constituyen "las formas personales en que un profesor entiende a los estudiantes, la naturaleza del aprendizaje, la sala de clases, el rol del profesor en el aula, los objetivos pedagógicos" (Borg, 2003, p. 100). ciencia sobre su práctica profesional para mejorar su formación y sus prácticas pedagógicas (Cortazzi y Jin, 1999; Nikitina y Furuoka, 2008). ${ }^{4}$

La metáfora constituye, entonces, como lo afirma Saban (2006), una poderosa herramienta cognitiva para aquellos profesores que están en búsqueda de su identidad. Estos pueden así llegar a comprender las circunstancias profesionales en las que se encuentran involucrados e incluso lograr cambios en su filosofía personal sobre la enseñanza (Saban, 2006, 2010). La metáfora cumple entonces un rol medular en la recolección y análisis de datos en el área educacional así como en otros dominios de la actividad social.

Por tal motivo, al igual que la investigación de Alarcón (2015), este trabajo se inserta en el fértil campo de estudio de las metáforas conceptuales que guían la vida cotidiana en el ámbito educacional. Seguimos aquí la línea de investigaciones que abordan las creencias sobre el universo de la enseñanza-aprendizaje mediante el estudio de representaciones metafóricas, entre otras Oxford et al. (1998), Cortazzi y Jin (1999), De Guerrero y Villamil (2002), Cameron (2003), Saban (2004, 2006), Saban et al. (2007), Zapata y Lacorte (2007), Low (2008), Nikitina y Furuoka (2008), Northcote (2009), Kasoutas \& Malamitsa (2009), Wan, Low y Li (2011), Thomas y Beauchamp (2011), Mellado et al. (2014, 2016, 2017), Alarcón (2015), Alarcón et al. (2015), Xiong et al. (2015), Dávila et al. (2017), Jin y Cortazzi (2017).

Algunas investigaciones analizan la evolución de las creencias docentes sobre enseñanza y aprendizaje, la interacción profesor-estudiante y las actitudes de los profesores en formación y en ejercicio (Bullough, 1991; Knowles, 1994; Dooley, 1998; Mahlios y Maxon, 1998; Leavy, Mc Sorley y Boté, 2007).

En este estudio, indagamos particularmente en los modelos docentes desde la perspectiva de

4 Focalizando la influencia de las creencias de los estudiantes sobre su propia conducta, Riley (1997) establece una correspondencia entre sistemas de creencias y metáfora conceptual: esta ayuda a los aprendientes no solo a explicitar sus creencias sino a organizarlas (1997, pp. 128, 143). 
los docentes en formación. En efecto, la visión ubicua de los estudiantes de profesorado resulta particularmente interesante: perciben el modelo docente tanto desde su posición de aprendientes como desde su proyección de desempeño profesional.

Precisamente, en la etapa de formación, la investigación en metáfora puede ayudar a los futuros profesores no solo a familiarizarse con las metáforas que guían su propio accionar sino también a elaborar nuevas metáforas consistentes con los modelos de enseñanza que buscan implementar (Mellado et al., 2017, p. 151).

Cabe agregar que, frecuentemente, no se trata de un modelo único y unívoco: las percepciones se encuentran basadas en conjuntos de metáforas entre las que existen superposiciones. ${ }^{5}$

Los modelos cognitivos relativos a la docencia son eminentemente dinámicos: así lo han probado estudios sobre la variación de las creencias en los docentes según sus años de experiencia profesional (Alger, 2009; Thomas y Beauchamp, 2011) y su contexto de desempeño (Ben-Peretz, Mendelson y Kron, 2003; Leavy, McSorley y Boté, 2007).

En tal sentido, este estudio ofrece un primer acercamiento a la evolución que se produce durante el transcurso del trayecto formativo de los futuros docentes: si bien el cuerpo de datos no habilita conclusiones definitivas, identifica la voz de los estudiantes que, próximos a concluir sus estudios, vislumbran la práctica profesional y la distinguen de aquella de quienes inician su formación docente.

\section{Metodología}

\section{Características del cuerpo de datos analizado}

Para constituir el corpus se adaptó el cuestionario abierto empleado en la universidad chilena que solicitaba a cada encuestado una expresión metafórica susceptible de caracterizar el dominio meta (el profesor) mediante un dominio fuente que le

5 A la misma conclusión llega, por ejemplo, la investigación de Xiong et al. (2015) entre los docentes de inglés en las universidades de China: el profesor puede ser visto al mismo tiempo como instructor, transmisor y constructor. prestara su estructura. ${ }^{6}$ Siguiendo esta premisa, se interrogó a cada informante sobre (i) cómo ve al profesor la sociedad argentina, (ii) cómo lo ve cada encuestado en su opinión personal, (iii) cómo ve cada informante al estudiante de profesorado. En cada caso, se debía justificar la imagen elegida. De este modo, el instrumento permite identificar las representaciones sociales relativas al docente, ${ }^{7}$ la percepción de los estudiantes sobre el docente $\mathrm{y}$, finalmente, la autopercepción de los estudiantes de profesorado.

\section{Procedimiento de análisis}

Se usó como marco de referencia el estudio realizado por Saban (2004), en el que se agrupan las metáforas bajo análisis en dos grandes perspectivas: (i) perspectiva centrada en la transmisión de conocimientos y el rol protagónico del docente, y la (ii) perspectiva orientada principalmente a la facilitación del aprendizaje y la participación activa de los estudiantes. A estas categorías se agregaron las que surgieron del análisis de Alarcón (2015): (iii) las metáforas centradas en la valoración social del profesor y (iv) del estudiante de pedagogía.

Se aplicó el mismo procedimiento de Alarcón (2015) para la identificación de metáforas conceptuales. Este consiste en la lectura y codificación de los cuestionarios seguida de la identificación de las expresiones metafóricas en los enunciados. Para ello se toma en consideración el contraste entre el significado básico (concreto) y el significado contextual, es decir, aquel que tiene en el dominio de la educación (dominio meta), según la propuesta del Pragglejaz Group (2007). Posteriormente se agruparon los enunciados con un dominio meta y dominio fuente común, correspondientes a una

6 Para facilitar la tarea de los encuestados, se brindó primeramente una breve definición de la metáfora y se dieron ejemplos fuera del ámbito de la educación.

7 Según Moscovici (1961) y Jodelet (1997), la representación social es una cierta forma de pensamiento colectivo orientado hacia la comprensión e interpretación del entorno social, material e ideal. Bajo la influencia del contexto en el que se elaboran, estas representaciones, con un rol cognitivo de construcción de la realidad, engendran opiniones y orientan el comportamiento social generando una identidad individual y grupal compatible con los valores consciente 0 inconscientemente compartidos. 
misma metáfora conceptual. Finalmente se identificaron las propiedades del dominio fuente con las que se configura el dominio meta para establecer los aspectos destacados por cada metáfora.

\section{Sujetos}

El cuestionario se aplicó en noviembre de 2015 a 31 estudiantes de los Profesorados en alemán, francés y portugués del Instituto de Enseñanza Superior en Lenguas Vivas "Juan R. Fernández" de la Ciudad Autónoma de Buenos Aires. ${ }^{8}$ La elección de otras lenguas que no fueran el español y el inglés, presentes en los resultados de Alarcón (2015), respondió a la voluntad de ampliar el universo de respuestas para identificar coincidencias que superaran las eventuales afinidades generadas por las lenguas-culturas objeto de estudio e hicieran foco en la docencia de modo general.

Asimismo, buscando detectar una evolución en las percepciones de los informantes en el curso de su formación, se aplicó el cuestionario a estudiantes de diversos niveles: 19 de nivel inicial (alumnos que cursan entre 1 y 10 materias), 6 de nivel intermedio (que acreditan entre 11 y 20 asignaturas) y 6 de nivel superior (que consignan más de 21 materias cursadas y/o en curso). Si bien no se trata de una muestra de dimensiones importantes, se presta a un primer estudio cualitativo.

Para el análisis de datos, se identificaron y sistematizaron las metáforas conceptuales según las categorías propuestas por Alarcón (2015), a las cuales se agregaron, en algunos casos, nuevas categorías. ${ }^{9}$ El análisis cualitativo de los resultados permitió no solo caracterizar las metáforas conceptuales que subyacen en la concepción de los informantes

8 En la ciudad de Buenos Aires, la formación de docentes en Lenguas Extranjeras para el nivel medio y superior no se realiza en la Universidad sino que se imparte, dentro de la educación de gestión estatal, en dos Institutos de Formación Docente. Para esta investigación, se encuestó a estudiantes del Instituto de Enseñanza Superior en Lenguas Vivas "Juan R. Fernández".

9 Tal sistematización no supone la existencia de categorías encapsuladas. Lejos de plantear una concepción binaria, este trabajo propone una visión holística: de hecho durante el análisis de datos se identificó la existencia de cruzamientos y superposiciones entre categorías (ver "El profesor como autoridad" y " El profesor como cuidador"). argentinos sino también visibilizar las convergencias y divergencias de las respuestas obtenidas con las de los estudiantes chilenos. Adicionalmente, se trató de manera comparativa (pero integrada) la opinión personal de los informantes y lo que estos perciben como representación social con respecto al docente. Tal tratamiento permitió resaltar coincidencias y discrepancias entre la visión personal de los estudiantes y su percepción de estereotipos sociales sobre los docentes.

En las siguientes páginas, analizamos los resultados obtenidos. El apartado 3 aborda las metáforas sobre el profesor en ejercicio, tanto desde la perspectiva de la sociedad en general como desde la opinión personal de los encuestados. En el apartado 4 , se estudian las metáforas sobre el docente en formación.

\section{Resultados y análisis de las representaciones metafóricas sobre el profesor}

Las categorías conceptuales analizadas en este apartado dan cuenta de las representaciones sociales percibidas por los estudiantes. Pero, como dialéctica ineludible entre lo colectivo y lo individual en el campo social, el análisis también toma en cuenta la opinión personal de los encuestados a fin de obtener más elementos de apreciación tanto por impregnación e influencia como por contraste.

\section{Metáforas centradas en el} proceso de enseñanza

Alarcón (2015, p. 182) encuentra cuatro categorías conceptuales para la perspectiva centrada en el profesional de la enseñanza: el profesor como transmisor de conocimientos, como figura de autoridad superior, como artesano y como reparador. Tales categorías también aparecen en las respuestas provistas por los estudiantes argentinos, con un orden de frecuencia similar.

Sin embargo, se advierten algunas particularidades, entre ellas la neta predominancia de la imagen del profesor como transmisor de conocimientos. Se registra, paralelamente, una menor importancia de 
la figura de autoridad que aparece en proporción similar a la imagen del artesano, seguida de la figura del profesor como reparador.

Observemos las respuestas obtenidas para cada categoría.

\section{El profesor como transmisor de conocimientos}

Entre las respuestas obtenidas en el estudio chileno, Alarcón (2015, p. 182) destaca la concepción activa del docente como transmisor de conocimiento en un esquema de emisión y recepción. ${ }^{10}$ En las representaciones detectadas entre los estudiantes chilenos, aparece de manera destacada la imagen del libro y la biblioteca como fuentes de conocimiento, seguida de la metáfora de la luz. ${ }^{11}$

El cuerpo de datos recogidos en la ciudad de Buenos Aires no brinda ocurrencias correspondientes a la metáfora de la luz — que sí surge en la caracterización del estudiante de profesorado (apartado 4) En cambio, se constatan coincidencias con los resultados registrados entre los estudiantes chilenos, el profesor es comparado con un libro de modo recurrente (11 casos sobre un total de 13) tanto por los cursantes de primer año como por los de cuarto. No obstante, cabe señalar que la entidad "libro" es objeto de caracterizaciones orientadas tanto positiva como negativamente.

Se oponen claramente, en estas metáforas, la opinión personal de los informantes y su percepción acerca de la visión imperante en la sociedad. Tal divergencia se materializa a través del contraste entre el libro en uso que metaforiza al docente en la opinión personal de los estudiantes y el libro en

10 Según un paradigma centrado en el docente, el conocimiento se transmite del profesor a los estudiantes, quienes cumplen un rol pasivo de receptor de saberes. En cambio, en una perspectiva centrada en el aprendiente, los estudiantes construyen conocimiento y se involucran activamente: el rol del profesor es el de un facilitador que acompaña el proceso de aprendizaje (McManus, 2001) tal como se desarrolla en el apartado "El profesor como facilitador 0 andamio".

11 El profesor como fuente de luz aparece en estudios realizados en variados entornos culturales, por ejemplo, en Nikitina y Furuoka (2008), según datos brindados por informantes universitarios de Malasia, y en Jin y Cortazzi (2017), según datos aportados por estudiantes y docentes de universidades de China e Irán. Esta metáfora subyace en las imágenes del sol, la luna, una estrella, una vela o el fuego. desuso que encarna la depreciación del docente por parte de la sociedad argentina.

Así, en el ejemplo (1), un estudiante justifica la metáfora "el profesor es como un libro al alcance de los estudiantes" aludiendo a la disponibilidad del docente:

(1) Porque cuando el alumno tiene una duda puede ir y consultarlo como si de una biblioteca se tratara, siempre abierto y a disposición. [Profesorado en francés, nivel inicial]

En cambio, las metáforas "el profesor es como un libro antiguo lleno de polvo que nadie usa" (2), "un libro viejo y guardado" (3), o "un libro viejo con páginas amarillas" (4), perfilan la visión negativa de la sociedad argentina sobre los profesores, tal como puede apreciarse en la justificación propuesta para cada una de estas imágenes:

(2) Tiene mucho para dar, pero es menospreciado, desvalorizado por la sociedad argentina, incluso olvidado. [Profesorado en portugués, nivel inicial]

(3) La sociedad no lo respeta, no lo valora. [Profesorado en portugués, nivel inicial]

(4) El profesor está obsoleto, está marcado en nuestra sociedad como alguien que se puede reemplazar por las nuevas tecnologías. [Profesorado en portugués, nivel intermedio]

Dentro del mismo dominio, además de la categoría básica "libro", pueden encontrarse especificaciones: aparecen tres miembros de la categoría de nivel subordinado, diccionario, enciclopedia y atlas universal.

Los dos primeros se encuentran tanto en la percepción social como en la opinión personal de los estudiantes. Aquí también se advierte la oposición entre la visión que se atribuye a la sociedad, con un marcado desinterés por los docentes, y el sentir de los estudiantes. Así, en (5) y (6) prevalece la desvalorización del profesor:

(5) [El profesor es visto como un diccionario] Porque es donde se encuentra el saber, pero que hoy en día está desvalorizado. [Profesorado en portugués, nivel inicial] 
(6) [El profesor es visto como una enciclopedia] Es visto como fuente de saber, como material de consulta, que no siempre se consulta ni todos tienen acceso [sic]. [Profesorado en francés, nivel inicial]

Solamente un caso alude a la imagen enciclopédica del docente:

(7) [El profesor es visto como una enciclopedia] Porque el ideal de profesor que tiene la sociedad es aquel que tiene una respuesta para todo. [Profesorado en portugués, nivel inicial]

La opinión personal de los estudiantes coincide en la metáfora libresca (diccionario, enciclopedia, atlas) como síntesis del saber:

(8) [El profesor es como un diccionario] En el caso de LE, en general, tienen amplio vocabulario y suelen responder rápidamente las preguntas referidas a eso [sic]. [Profesorado en portugués, nivel intermedio]

(9) [El profesor es como una enciclopedia general] Porque puedo consultarle sobre una amplia variedad de temas más allá de su materia y aprender de ellos. [Profesorado en portugués, nivel inicial]

(10) [El profesor es como un Atlas universal] Porque nos enseña, nos brinda la información que necesitamos y, además, nos cuentan y muestran el mundo abriéndonos caminos [sic]. [Profesorado en portugués, nivel inicial]

Nótese la concepción acumulativa que permea la visión de los estudiantes: los volúmenes elegidos representan el prototipo de la suma del conocimiento ordenado de manera metódica: el diccionario como nomenclatura (ligado a la idea del profesor de lengua como diccionario viviente), la enciclopedia como compendio del saber universal, el atlas universal, asociado al conocimiento del mundo.

En (9) y (10), se vislumbra asimismo la implicación de los estudiantes, su vivencia personal del contacto con el profesor, materializada por el uso de la primera persona ("puedo consultarle", "nos enseña", "necesitamos", "nos cuentan", "abriéndonos caminos").

De modo coincidente, para los estudiantes, la sociedad argentina identifica la tarea del docente con la provisión de conocimiento; este es visto como un proveedor:

(11) Generalmente se lo considera como el que provee el conocimiento, el que tiene todo para dar a alguien que está sin provisión. [Profesorado en francés, nivel superior]

Así, socialmente parece imperar la metáfora ontológica (Lakoff y Johnson, 1980, p. 26) del saber como UN OBJETO QUE SE TRASPASA ${ }^{12}$. Tal metáfora, central en la concepción de la educación como transmisión cultural (Oxford et al., 1998), se relaciona estrechamente con la metáfora del conducto (Reddy, 1993 [1979]) que asimila el lenguaje a un simple vehículo para la transmisión de información. ${ }^{13}$

Sin embargo, aunque con una marcada diferencia de frecuencia, se encuentra también la categoría del profesor como un representante de la autoridad.

\section{El profesor como figura de autoridad}

Asociada al mantenimiento del orden social (Oxford et al., 1998), la figura de autoridad puede materializarse en roles tales como el de juez, oficial de policía, guardián penitenciario, árbitro, director de orquesta, o jefe de familia, según datos de Cortazzi y Jin (1999).

Las respuestas de la encuesta realizada en Chile muestran dos dimensiones de tal categoría: (i) el profesor como figura de autoridad respetada por su conocimiento y (ii) el profesor como autoridad que supervisa, controla el éxito académico e impone reglas. Entre las imágenes provistas por los encuestados figuran, por un lado, las representaciones de tipo arquitectónico en torno a los conceptos de pilar, base y pieza de construcción y, por otro, las referencias a funciones de vigilancia y sanción, materializadas en el supervisor, el jefe de pueblo y el verdugo (Alarcón, 2015, p. 183).

12 Para la transcripción de las metáforas conceptuales, seguimos el empleo de versales [mayúsculas] adoptado por Lakoff y Johnson (1980).

13 En esta idea, las unidades léxicas constituyen contenedores para el sentido que es envasado y transportado desde el hablante hasta el oyente. Para una crítica de esta visión, ver Langacker (1987). 
En la encuesta argentina, la figura de autoridad, con menor frecuencia de aparición, reviste tres formas: el juez, el jefe de familia y un Dios, las dos primeras asociadas a la percepción de la sociedad y la última a la opinión personal de un informante.

En el primer caso, se percibe la idea de juicio y sanción:

(12) [Los profesores son como un juez] Porque van a enseñarles acerca de lo que es correcto $e$ incorrecto y van a aplicar sanciones en caso de que sea necesario para corregir una conducta. [Profesorado en portugués, nivel inicial]

En el segundo caso, la idea de autoridad se superpone a la del profesor como cuidador con actitud paternalista. ${ }^{14}$ Así, la sociedad concibe al docente como un jefe de familia:

(13) Porque en muchas ocasiones se ocupa de las distintas necesidades de los niños y adolescentes. Se ocupa de trabajar los valores, es una figura de autoridad y en el caso de la escuela primaria también se ocupa de alimentar a los niños. [Profesorado en alemán, nivel intermedio]

En cuanto a la comparación entre el docente y un Dios, el profesor, más allá del conocimiento disciplinar, aparece como una figura tutelar con autoridad moral:

(14) Porque, si bien puede no saberlo todo, generalmente está en todo, con todos (sus alumnos), sabe mucho (porque estudia mucho), puede perdonar ciertas cosas, etc. [Profesorado en portugués, nivel superior]

Con la misma frecuencia, aparece la figura del profesor como artesano.

\section{El profesor como artesano}

Según los resultados obtenidos por Alarcón (2015, p. 183), el docente como artesano se inserta en el marco de una educación concebida como producción según patrones establecidos, a tal punto que puede ser asimilado a una máquina procesadora.

14 Como se ha señalado, el solapamiento entre metáforas conceptuales, por ejemplo entre el profesor como autoridad y el profesor como cuidador, confirma su sistematicidad.
Según Oxford et al. (1998), esta metáfora reduce el rol del docente al de instrumento de producción dentro de una visión de la educación como factor de orden social.

A este respecto, las respuestas de los estudiantes argentinos manifiestan una doble perspectiva: para los encuestados, la sociedad sitúa al docente como agente de un proceso de construcción mientras que, en su opinión personal, el profesor es fundamentalmente un creador.

Así, para la sociedad, el profesor es un obrero que

(15) Tiene que construir y ayudar a colocar los "ladrillos" (conocimientos) para que estos queden bien firmes y se pueda seguir construyendo arriba de ellos. [Profesorado en portugués, nivel intermedio]

En cambio, la opinión personal de los informantes atribuye al profesor un trabajo de creación y lo caracteriza como artesano o incluso como artista:

(16) [El profesor es como un artesano] Porque debe crear, cada día, con sus propias herramientas una forma mejor, perfeccionada, de las infinitas posibilidades de transmisión de un saber, de una nueva imagen que exprese ese saber con el amor de quien crea algo, hace nacer algo que le es muy propio. [Profesorado en francés, nivel intermedio]

(17) [El profesor es como un artista] Porque con aquello que tiene crea una obra, llámese clase, situación de enseñanza o incluso la propia mente del niño. No hay dos obras iguales. Y además busca en su arte despertar sensaciones, pensamientos, ideas. Motivar, emocionar. [Profesorado en francés, nivel inicial]

Nótese que, si el docente es visto como un creador, el papel de los estudiantes se reduce al del material con el que este generará su obra. Estas imágenes remiten a la metáfora del docente como alfarero (De Guerrero y Villamil, 2002) que moldea la arcilla, es decir, a sus alumnos (ver apartado "El estudiante de profesorado como un ser vivo en desarrollo").

La última categoría identificada en el corpus es la del profesor como reparador. 


\section{El profesor como reparador}

De los datos analizados en Alarcón (2015, p. 183), surge la imagen del docente como "un instrumento ortopédico" con función reparadora para corregir los errores de los estudiantes. Esta misma imagen aparece, con matices, en las respuestas de los encuestados argentinos: la sociedad ve al profesor como un vendaje o aquello que viene a llenar espacios vacíos:

(18) En el caso del bendaje [sic], incluso a llenar aquellos que se encuentra herido [sic], en falta.

Llenar el vacío del hogar, de la falta de comida por situaciones económicas, de atención de salud y en algún lado queda el conocimiento. [Profesorado en francés, nivel inicial]

El trabajo de Alarcón (2015, pp. 184-185) considera no solo las metáforas orientadas hacia la enseñanza sino también aquellas que, desde la perspectiva del estudiante, apuntan al proceso de aprendizaje.

\section{Metáforas centradas en el proceso de aprendizaje}

En el cuerpo de datos obtenido en Chile, se encontraron tres categorías conceptuales orientadas hacia el proceso de aprendizaje: el profesor como cuidador, como líder cooperativo y como facilitador o andamio (Alarcón, 2015, pp. 184-185).

En las respuestas obtenidas en Argentina, se encuentran las mismas categorías aunque con diferente orden de importancia. Predomina la figura del profesor como líder cooperativo, seguida de la imagen del profesor como andamio y, por último, la metáfora del profesor como cuidador.

\section{El profesor como líder cooperativo}

Dentro de esta categoría, en la que los estudiantes cumplen un rol activo, se identifican, en el estudio chileno, las figuras del guía, el pastor y el entrenador deportivo junto con la imagen del puente.

En el estudio realizado en Buenos Aires, también aparece la imagen del guía en las opiniones personales de los encuestados:
(19) [El docente es como un guía de los boy scouts] Porque viven dándonos herramientas para que "sobrevivamos" en esta carrera, pero a la vez en algún punto nos dan el espacio para que seamos nosotros los que actuemos. [Profesorado en portugués, nivel inicial]

Con la misma funcionalidad, aparece un objeto altamente simbólico, la brújula:

(20) [El docente es como una brújula] Porque es el que marca el camino y lo ilumina para que seas una persona mejor. [Profesorado en portugués, nivel inicial]

(21) Porque su trabajo es guiar al estudiante hacia el conocimiento y sobre todo indicarle el camino [Profesorado en francés, nivel intermedio]

(22) Porque está a la disposición de los alumnos para guiarlos hacia donde ellos quieran dirigirse.

[Profesorado en alemán, nivel avanzado]

El concepto del aprendizaje como trayecto (metafóricamente, LA FORMACIÓN ES UN CAMINO A RECORRER), ${ }^{15}$ aparece no solo en la conceptualización del docente como guía o brújula sino también en la imagen de la brisa que empuja un navío hacia su destino:

(23) [El docente es como una brisa] Porque debe empujar suavemente a nuevos lugares de conoci-

miento. [Profesorado en francés, nivel inicial]

En otros casos, el profesor es visto como un embajador (con una clara alusión al concepto de puente, detectado en los resultados del estudio chileno), metáfora particularmente significativa en la conceptualización del profesor de lengua extranjera:

(24) [El docente es como un embajador] Porque media y regula en la relación que tienen sus alumnos con el saber y entre ellos mismos, en especial en términos de comunicación y lenguaje, como lo

15 Como se verá en el apartado "El estudiante de profesorado como un ser vivo en desarrollo", en la conceptualización del trayecto formativo como un viaje, el docente cumple una función de guía o brújula mientras que el estudiante es conceptualizado como un viajero, un aventurero. En el caso particular del aprendizaje de una lengua extranjera, Caballero (2006), registra la pregnancia de la metáfora APRENDER ES EMPRENDER UN VIAJE, estructura compleja en la que los aprendientes recorren un camino guiados por el docente. 
hace un embajador que es puente entre culturas.

[Profesorado en alemán, nivel inicial]

La segunda categoría en orden de frecuencia es el profesor como facilitador $\mathrm{y}$, fundamentalmente, como andamio.

\section{El profesor como facilitador o andamio}

Esta categoría aparece en el estudio chileno bajo la forma de la imagen metafórica de la ventana abierta hacia el conocimiento (Alarcón, 2015, p. 185). La noción de apertura se encuentra también en las respuestas de los encuestados argentinos bajo la forma de la metáfora del profesor como cerrajero:

(25) [El docente es como un cerrajero] Con técnicas y métodos abre puertas en el alumno para que este ingrese al conocimiento. [Profesorado en francés, nivel avanzado]

Otras metáforas producidas por los informantes argentinos privilegian la figura de la base de sustentación: un andamio, un soporte, las columnas de un edificio:

(26) [El docente es como un andamio] Porque nos da las herramientas necesarias para que lleguemos a nuestras metas sin obligarnos a seguir su ritmo, sino proporcionando un soporte para que podamos hacerlo. [Profesorado en alemán, nivel inicial]

(27) [El docente es como las columnas de un edificio] Porque es el que funda las bases de los conocimientos de los alumnos ayudándolos a crecer y va sosteniendo sus conocimientos a través de la respuesta de dudas o corrección de errores. El alumno crece como un edificio con la ayuda de profesores que hacen de columnas. [Profesorado en alemán, nivel intermedio]

Como lo señalan Oxford et al. (1998, p. 33) y Cortazzi y Jin (1999, p. 153), la metáfora del soporte temporario que se retira a medida que avanza la construcción se encuentra ampliamente extendida en educación a partir del concepto de scaffolding, desarrollado por Wood, Bruner y Ross (2006 [1976], p. 199). Esta noción, particularmente importante para la perspectiva constructivista en educación, se relaciona estrechamente con el concepto de asistencia y de zona de desarrollo próximo (Vygotsky, 1986 [1934], pp. 187-189).

Por último, los informantes argentinos proponen la metáfora del profesor como cuidador.

\section{El profesor como cuildador}

Según el cuerpo de datos analizado en Alarcón (2015, p. 184), la sociedad chilena ve al docente como un cuidador asociado, mayoritariamente, a la figura paternal y/o maternal y también como "una mano amiga en quien confiar" o "un jardinero". 16

De tales imágenes, solo la figura ascendiente del padre y/o la madre aparecen claramente en el corpus argentino tanto en la visión de la sociedad como en la opinión personal de los encuestados.

Así, la sociedad considera al docente como un padre o una madre ya que

(28) es quien aprueba o desaprueba determinadas conductas y es un referente directo para los alumnos. [Profesorado en portugués, nivel inicial]

(29) debe dar alimento, educación, contener y proporcionar cuidados maternales. [Profesorado en francés, nivel inicial]

Tal mandato social modela también la opinión personal de un estudiante:

(30) [El docente es como un padre] Cuida a sus alumnos, les da el mejor ejemplo de cómo hacer las cosas, porque los ayuda y los guía, los apoya en sus ideas. Además los instruye, les enseña a diferenciar lo bueno de lo malo. Es una figura de autoridad. [Profesorado en francés, nivel inicial]

Nótese nuevamente la superposición de determinadas categorías identificadas en estos estudios: la figura del padre cuidador se superpone con la de autoridad presentada en "El profesor como artesano". En efecto, como se ha señalado, las categorías empleadas aquí como dispositivo de análisis no constituyen compartimientos estancos sino que se insertan en un entramado complejo.

16 La imagen del profesor como figura nutricia que toma a su cargo el cuidado de sus alumnos es recurrente en estudios realizados en variados entornos culturales, entre otros Oxford et al. (1998), Cortazzi y Jin (1999), De Guerrero y Villamil (2002), Nikitina y Furuoka (2008). 
En el siguiente apartado nos ocuparemos particularmente de las metáforas que reflejan, en ocasiones, una singular desafección social por el profesor.

\section{Metáforas centradas en la} valoración social del profesor

Como refiere Alarcón (2015, pp. 185-187), en el estudio chileno se encontraron metáforas que dan cuenta de la valoración social de los docentes: el profesor es visto, negativamente, como un ser despreciado y como un empleado o, al contrario, positivamente, como un héroe en contadas oportunidades.

De modo coincidente, los datos del corpus argentino configuran, en general, una visión negativa de los docentes (ser despreciado, empleado). ${ }^{17} \mathrm{Sin}$ embargo, no aparece en la valoración social la figura del héroe, como en el corpus chileno, sino, de modo menos luminoso, la del mártir. La ambigüedad en el juicio social sobre los docentes aparece claramente en la figura del docente como un "híbrido creado a partir de los personajes de la fábula 'La cigarra y la hormiga"' justificada del siguiente modo:

(31) Porque la mirada que tiene la sociedad argentina es contradictoria y se debate constantemente entre dos ideas de lo que es un profesor. Por un lado, alguien que trabaja arduamente y sin parar (la hormiga) en la formación de personas. $Y$ en muchos otros casos, el profesor es visto como alguien que no trabaja demasiado y tiene mucho tiempo de vacaciones (la cigarra). [Profesorado en francés, nivel avanzado]

Observemos primeramente las metáforas que construyen, para el profesor, la imagen de un ser despreciado.

\section{El profesor como un ser despreciado}

17 Por ejemplo, escribe Urdinez en La Nación el 1 de marzo de 2014: “Desde la opinión pública, los medios de comunicación y el decir de muc hos padres y alumnos, los docentes son responsables aunque no los únicos- del profundo fracaso que experimenta la escuela argentina, que las últimas pruebas PISA sólo [sic] vinieron a reconfirmar".
Si en Chile la imagen social negativa con respecto a los docentes adopta la forma de metáforas tales como "el patito feo", "un insecto", "una moneda de \$10", "un tesoro sin valor", "un engranaje desvalorado", etc. (Alarcón, 2015, p. 186), para los encuestados argentinos, la sociedad asocia a los docentes, negativamente, con políticos, asistentes de cocina, títeres, plastilinas y máquinas.

La imagen desvalorizada del político se asocia a la inutilidad:

(32) [El docente es como un político] Es inútil, solo está ahí, pero no ocupa ninguna función esencial. Es decir, tiene un puesto de trabajo pero no cumple con su función. [Profesorado en francés, nivel inicial]

La misma nulidad se sintetiza en la imagen del poste; en el imaginario colectivo urbano, esta columna, que sirve de apoyo o señal, recibe escasa consideración:

(33) [El docente es como un poste] Porque no se lo considera útil para nada, sino que solo ocupa un espacio en el frente, y está cubierto de papeles pegados descuidadamente, como si de un espacio público se tratara, sin posibilidad de defenderse. ${ }^{18}$

[Profesorado en francés, nivel inicial]

Otra expresión metafórica para caracterizar al docente como ser menospreciado es la de una máquina destinada a la transmisión de conocimientos como un mero proceso de producción: ${ }^{19}$

(34) [El docente es como una máquina que no debe equivocarse] Más a menudo la función del profesor es vista como un mero robot que transmite conocimientos muchas veces considerados intrascendentes. [Profesorado en francés, nivel inicial]

(35) [El docente es como una máquina de una fábrica] Porque trabaja sin parar, puede que no se

18 En la ciudad de Buenos Aires, los postes de iluminación y otros elementos del mobiliario urbano se encuentran, en ocasiones, cubiertos de carteles de publicidad ilegal que promocionan todo tipo de servicios.

19 Se advierten coincidencias con la imagen del profesor como artesano, en el marco de la producción industrial, tal como aparece en la encuesta realizada entre estudiantes chilenos (Alarcón, 2015, p. 183). 
le den los cuidados que necesita, la importancia que se merece, ya que en el conjunto ayuda a la "producción" (pero ¡ojo! aquí producción en términos de educación no como homogeneizadora y sí por la cantidad de alumnos que pueda llegar a tener). [Profesorado en portugués, nivel avanzado]

Asimismo, el docente asoma como personaje subalterno en la metáfora del asistente de cocina:

(36) [El docente es como un asistente de cocina] Aunque es tan indispensable como el cocinero y de hecho, muchas veces, es quien más se responsabiliza en comparación a "sus mayores"; su rol es dejado de lado como si su participación fuese accesoria y de poca importancia en el resultado final. [Profesorado en francés, nivel inicial]

Como forma de subordinación aparece también la imagen del títere $y$, de modo más polisémico, la metáfora de la plastilina:

(37) [El docente es como un títere] Lo manejan desde el sistema educativo para enseñar, no siempre todo cuanto sabe, sino lo que se establece. $\mathrm{Y}$ en muchos casos no se lo respeta ni valora. [Profesorado en alemán, nivel inicial]

(38) [El docente es como una plastilina] Hoy en día se lo puede moldear a gusto de los padres o los alumnos. Ya no es visto como una figura rígida. También se podría decir que logra adaptarse a las circunstancias o a su sueldo. [Profesorado en alemán, nivel avanzado]

Esta última caracterización, relacionada con su condición laboral, se relaciona estrechamente con la metáfora del docente como empleado.

\section{El profesor como un empleado}

Si en el corpus chileno la visión social sobre el docente se metaforiza a través de las imágenes de "un cajero de banco", "un soldado" o "una niñera" (Alarcón, 2015, p. 186), según la encuesta argentina, la sociedad parece ver al profesor como un oficinista o, incluso, como un aprovechador, por ejemplo,

(39) [El docente es como un oficinista] Porque va, hace su trabajo y se vuelve sin involucrarse con sus alumnos (o clientes en este caso). [Profesorado en francés, nivel intermedio]

(40) [El docente es como un chanchito que se cuelga de la teta de mamá chancha y succiona plácidamente] Existe una hipergeneralización con respecto al profesor en el sentido de que se cree que son personas poco capaces que quieren tener un sueldo del Estado y donde nadie les exija cumplir con su trabajo. [Profesorado en francés, nivel inicial]

En este último caso, la imagen se asocia a la supuesta ineficiencia y ociosidad atribuida a los empleados estatales. La contrapartida de esta visión negativa, la ofrece la figura del profesor como ser sacrificado que lo ofrece todo por su profesión.

\section{El profesor como un mártir}

En esta categoría, opuesta a la del apartado anterior, el docente está dotado de características positivas: trabaja sin pensar en su baja remuneración y se sacrifica por su profesión. ${ }^{20}$

(41) [El docente es como un mártir] Porque se sacrifica por su profesión. A pesar del bajo salario y el trabajo extra que no es considerado continúa trabajando por sus alumnos. [Profesorado en alemán, nivel avanzado]

En el siguiente apartado, nos ocuparemos de las metáforas que construyen la visión que de sí mismos tienen los docentes en formación.

\section{Resultados y análisis de las representaciones metafóricas sobre el estudiante de profesorado}

El estudio realizado en Chile identificó las siguientes categorías para las representaciones metafóricas del estudiante de pedagogía: un ser vivo en desarrollo, un transmisor de conocimiento, un héroe, un ser despreciado, un aventurero, un soldado, un líder cooperativo y un mártir (Alarcón, 2015, pp. 188-189).

20 La asociación entre docentes y sacrificio personal también se encuentra presente en los resultados obtenidos por Jin y Cortazzi (2017) sobre datos provistos por informantes de China e Irán. 
Las imágenes presentes en los datos recopilados en Buenos Aires exhiben coincidencias con tales resultados pero difieren en la importancia relativa de las categorías citadas. Los profesores en formación se perciben a sí mismos, en primer lugar, al igual que en Chile, como seres vivos en desarrollo pero, en segundo lugar, como aventureros. Luego aparece, sin mayores diferencias, la caracterización del profesor en formación como transmisor de conocimiento, héroe, ser despreciado y soldado. No se registran ocurrencias de las imágenes de líder cooperativo y de mártir. En su lugar, aparece la imagen del artesano.

\section{El estudiante de profesorado como un ser vivo en desarrollo}

Como lo afirma Alarcón (2015, p. 189), las imágenes metafóricas propuestas por los estudiantes revelan su conceptualización de los años de formación como un período de crecimiento. Por tal motivo, los estudiantes chilenos evocan imágenes de un ser en desarrollo. ${ }^{21}$ Se registran alusiones a vegetales (árbol, semilla), objetos culturales (libro inconcluso), seres humanos (aprendiz de hechicero) o animales (pollito), incluso "una luz que se quiere convertir en estrella".

Los datos obtenidos en Argentina resultan coincidentes: la categoría ser vivo en desarrollo es predominante en las respuestas aunque se registra una leve variación en la naturaleza de los seres evocados: aparece la imagen del niño, luego la del libro o cuaderno que se inicia - con énfasis en el proceso de escritura-, el vegetal (una semilla, una planta) y finalmente el animal en desarrollo (un renacuajo). Se agrega, además, la imagen de una obra en arcilla:

(42) [El estudiante de profesorado es como un niño] Está en una etapa de aprendizaje. Todo en su alrededor le parece nuevo, está predispuesto a acceder a nueva información. Cada día aprende algo nuevo. [Profesorado en francés, nivel inicial]

21 La imagen de plantas en crecimiento también es identificada por Piquard (1996, según Riley, 1997, p. 143) en su investigación sobre las metáforas empleadas por los docentes franceses para referirse a los progresos de sus estudiantes. De modo más general, existe una estrecha asociación entre el aprendizaje y el crecimiento.
(43) [El estudiante de profesorado es como un libro que recién se empieza a escribir] El alumno del profesorado es alguien lleno de sueños que llega con muchas novedades e ilusiones. Su historia va a ser escrita en el día a día y su saber también. [Profesorado en portugués, nivel intermedio]

(44) [El estudiante de profesorado es como el proceso de crecimiento de una planta] Porque al empezar es el brote, y a medida que va avanzando, crece, se desarrolla, aprende, se equivoca, atraviesa obstáculos y los supera. Hasta que finalmente llega hasta el fruto. Luego el proceso vuelve a comenzar cuando comienza a ejercer la profesión. Es cíclico. [Profesorado en alemán, nivel inicial]

(45) [El estudiante de profesorado es como una obra en arcilla] Algo que aún no tiene forma pero la busca y sobre todo que es moldeado tanto en su búsqueda de devenir un profesor en particular y no otro pero también por todo aquello que lo toca. El cual debe luchar por eso a lo que apunta y eliminar lo que se pegue a él que sea un desperdicio.

[Profesorado en francés, nivel inicial]

Se advierte que, en este último caso, el estudiante de profesorado se conceptualiza a sí mismo como una materia sin forma, de gran plasticidad $y$, por contraste, se infiere el rol modelador del docente-alfarero.

Si la formación de los futuros docentes es asimilada, frecuentemente, al proceso de desarrollo de un ser vivo, también es vista como una aventura.

\section{El estudiante de profesorado}

\section{como un aventurero}

En esta categoría, la formación es conceptualizada como un proceso de descubrimiento y exploración. Como representación metafórica del estudiante, el estudio chileno menciona la imagen de un viajero, un astronauta, un alpinista y un pez en el océano.

Por su parte, los informantes de Buenos Aires citan la metáfora del viajero/viajante, el explorador, Cristóbal Colón al zarpar hacia nuevos mundos, un salmón que remonta el río, imágenes estrechamente relacionadas con la metáfora APRENDER ES EMPRENDER UN VIAJE, mencionada en la sección "El profesor como lider cooperativo". 
Observemos la perspectiva de dos encuestados de nivel avanzado: en (46) prevalece la mirada optimista y la valoración del recorrido, en (47) se adivina la desilusión:

(46) [El estudiante de profesorado es como un viajante] Se embarca hacia un destino. Programa el tiempo durante el cual va a viajar. Se detiene, avanza, encuentra pasos difíciles y trata de atravesarlos. Disfruta de lo que el viaje le ofrece. Mira a su alrededor, observa, reflexiona, se sitúa en un punto del trayecto recorrido y mira hacia atrás, hacia adelante y se maravilla. [Profesorado en francés, nivel avanzado]

(47) [El estudiante de profesorado es como Cristóbal Colón al zarpar hacia nuevos rumbos] Se embarca en un viaje sin conocer verdaderamente el puerto. Zarpa pensando que va en una dirección $y$ termina en otro lado impensado. El estudiante empieza su carrera lleno de ilusiones, en un mundo de fantasía. No es hasta llegar al aula que se da cuenta de que ese mundo no se asemeja al que imaginaba. [Profesorado en francés, nivel avanzado]

En cambio, en la respuesta de un estudiante de nivel intermedio permanece la proyección del camino formativo bajo la guía del docente:

(48) [El estudiante de profesorado es como un explorador (utilizando la metáfora del profesor como brújula)] Porque se embarca en un viaje en busca de conocimiento y experiencia que adquiere, puede adquirir de su docente. [Profesorado en francés, nivel intermedio]

En algunos casos, la metaforización se encuentra claramente vinculada con la futura realidad del docente en ejercicio. En (49), el estudiante de profesorado se aparta del camino preferido por la mayoría y opta por una profesión que no garantiza un buen salario.

(49) [El estudiante de profesorado es como el salmón] Porque nada contra la corriente. Es una profesión que hoy en día no es valorada como debería ser, no tiene los mismos rendimientos económicos que otros trabajos. La mayoría de las personas estudian pensando en tener un trabajo con un buen salario. [Profesorado en portugués, nivel inicial]

Las representaciones sobre el rol del docente esbozan la futura inserción profesional de los informantes. Así, algunas de las categorías asociadas al profesor aparecen también en la imagen que los estudiantes tienen de sí mismos en el futuro.

\section{El estudiante de profesorado como un transmisor de conocimiento}

Como indica Alarcón (2015, p. 190), esta categoría mantiene puntos de contacto con las respuestas propuestas para la metáfora del profesor como transmisor de conocimiento, con su correspondiente contraparte, el estudiante en el rol de receptor. Cabe resaltar que, en este caso, la proyección del estudiante como futuro docente permite cerrar el ciclo. Una figura frecuente en el estudio chileno es la de la esponja, el vaso, el libro y, en menor número, una grabadora, un portavoz, una luz.

En el cuestionario administrado en Argentina, también aparece la metáfora de la esponja que absorbe y transmite:

(50) [El estudiante de profesorado es como una esponja] Porque está listo para absorber todos los conocimientos a lo largo de la carrera en busca del día de mañana transmitirlo a sus alumnos. [Profesorado en portugués, nivel inicial]

Lo mismo sucede con la imagen del florero:

(51) [El estudiante de profesorado es como un florero] Porque debe tener lugar para alojar nuevos conocimientos para poder transmitirlos en el futuro y renovarlos (actualizarlos) cuando se vayan marchitando. [Profesorado en francés, nivel inicial]

En resumen, de acuerdo a la metáfora del conocimiento como UN OBJETO QUE SE TRASPASA, los estudiantes se perciben como receptores pero, en un futuro próximo, transmisores de conocimientos reproduciendo el ciclo de transferencia de saberes.

El estudiante de profesorado como un héroe 
Esta concepción se relaciona estrechamente con la carga negativa asignada a la profesión docente tanto en Chile como en Argentina. Tal desafección social confiere a la elección de la profesión docente un rasgo heroico. Los datos obtenidos en Chile sitúan al estudiante de pedagogía como un héroe o más particularmente como Don Quijote, Ulises, El Principito o un valiente tigre (Alarcón, 2015, p. 188).

Entre las respuestas, menos numerosas, de los informantes de Buenos Aires, aparece el león como arquetipo del luchador:

(52) [El estudiante de profesorado es como un león] Porque siempre se esmera a llegar a sus objetivos, lucha contra las adversidades y apasionado por lo que estudia [sic]. [Profesorado en francés, nivel intermedio]

Al igual que en el estudio realizado en Chile, en Argentina aparece la figura del alumno de profesorado como un ser menospreciado.

\section{El estudiante de profesorado}

como un ser despreciado

De modo coherente con la categoría El profesor como un ser despreciado, los docentes en formación de la universidad chilena se muestran conscientes de la evaluación social negativa con respecto a la profesión elegida. Sus respuestas evocan una bala perdida, un gato en una perrera, un pez fuera del agua, un fugitivo o un ermitaño (Alarcón, 2015, p. 189).

Las expresiones metafóricas propuestas por los informantes argentinos, inferiores en número, corresponden a un burro y a una marioneta. Emerge de las respuestas, principalmente, la percepción de las dificultades ligadas al esfuerzo realizado durante su formación docente:

(53) [El estudiante de profesorado es como un burro que persigue su zanahoria, y esta [sic] siempre se aleja] Porque es mucho el esfuerzo. $\mathrm{Si}$ bien uno tiene en claro que esta es su vocación, son muchos los obstáculos, las cosas que uno tiene que soportar. Burocracias, etc. [sic] [Profesorado en francés, nivel inicial]
La percepción del trayecto formativo como un camino sembrado de obstáculos aflora también en la visión del docente como un soldado.

\section{El estudiante de profesorado como un soldado}

En el corpus chileno, las expresiones metafóricas caracterizan al estudiante de pedagogía como alguien que se prepara para enfrentar obstáculos. Así, se registran las siguientes metáforas: un soldado sin armas, un voluntario militar, un cadete en el regimiento (Alarcón, 2015, p. 189).

En la encuesta argentina aparece un solo caso que coincide con esta categoría, el kamikaze que se juega la vida por su causa:

(54) [El estudiante de profesorado es como casi un kamikaze] Porque a pesar de las críticas que escucha sobre la educación, las conductas de los alumnos y de que tiene miedo sobre lo que va a venir, "se la juega" por sus convicciones. [Profesorado en portugués, nivel inicial]

En el estudio realizado en Chile, la metáfora del estudiante como un soldado, está seguida por las figuras del estudiante como líder cooperativo y mártir, categorías ausentes del corpus argentino. Las respuestas obtenidas en Buenos Aires permiten delinear la categoría del estudiante de profesorado como un artesano, metáfora ligada a la categoría del profesor con las mismas características.

\section{El estudiante de profesorado como un artesano}

Esta imagen, en el caso de los docentes en formación, se encuentra asociada a su trabajo actual para construir su saber y futura entrega profesional:

(55) [El estudiante de profesorado es como un obrero] Porque construye su conocimiento y va a construir el de los otros (sus futuros alumnos), porque se levanta bien temprano para trabajar (estudiar, trabajar y cursar), o sea que no tiene un solo trabajo. [Profesorado en portugués, nivel avanzado]

Se desprende de lo anterior que la percepción que de sí mismos tienen los estudiantes de profesorado integra dos dimensiones estrechamente entrelaza- 
das: por un lado, su trayecto formativo, visto como un camino sembrado de obstáculos, que requiere del heroísmo de un soldado y la abnegación de un artesano, $y$, por otro, el futuro desempeño profesional, imaginado como transmisión de conocimiento.

\section{Conclusiones}

En este estudio se ha evidenciado el valor de la metáfora como eficaz instrumento para descubrir las creencias de los sujetos sobre la profesión docente y sobre su identidad como profesores en formación. En efecto, el análisis de las metáforas obtenidas permite observar la complejidad de los conceptos metafóricos, ya que en ellos se distinguen los aspectos destacados por cada metáfora, por ejemplo, en el rol del profesor en el proceso de enseñanza. Al mismo tiempo, se identifica cómo los sujetos asumen las valoraciones que la sociedad asigna al profesorado.

Asimismo, esta investigación pone de manifiesto el carácter sistémico y reticular de las metáforas conceptuales que modelan nuestra percepción del mundo. Así, el rol del docente se inserta en un entramado de correspondencias en el que, por ejemplo, el docente es una brújula, el estudiante un aventurero $\mathrm{y}$ aprender es emprender un viaje.

Se debe destacar que - a pesar de las diferencias - hay coincidencias importantes entre el corpus argentino y chileno: en ambos contextos las metáforas centradas en la enseñanza dan cuenta de la concepción del conocimiento como objeto que se traspasa, aquellas centradas en el aprendizaje asimilan dicho proceso a un viaje o al crecimiento de una planta; finalmente, ambos estudios señalan la escasa valoración de la sociedad con respecto al docente.

Es pertinente aquí recalcar el papel que se le atribuye, en Lingüística Cognitiva, a la experiencia en la conformación de los conceptos. En otras palabras, es muy probable que nuestras realidades y contextos similares en lo relativo a las condiciones laborales del profesorado, así como a los modelos de enseñanza, expliquen las semejanzas en los resultados.

Con una visión más amplia -y de modo tangencial ya que no es el objetivo primero de este tra- bajo- vale resaltar que existen puntos de contacto con variados estudios realizados sobre datos de otras partes del mundo - Gran Bretaña (Oxford et al., 1998), China, Irán, Líbano, Turquía (Cortazzi y Jin, 1999), Puerto Rico (De Guerrero y Villamil, 2002), Malasia (Nikitina y Furuoka, 2008), entre otros-. Tal coincidencia confirma el poder heurístico de la metáfora conceptual y permite esbozar la existencia de un zócalo experiencial común en el dominio cognitivo básico de la educación.

\section{Referencias}

Alarcón Hernández, P. (2015). Representaciones metafóricas sobre el profesor en estudiantes de pedagogía de primer año. En P. C. Hernández, C. Borzi y M. S. Funes, (comp.), Cognición, metáfora y discurso (pp. 177-197). Mar del Plata, Argentina: Editorial Martín.

Alarcón, P., Díaz, C. y Vergara, J. (2015). Chilean preservice teachers' metaphors about the role of teachers as professionals. En W. Wan y G. Low, (eds). Elicited Metaphors Analysis in Educational Discourse (pp. 289-314). Amsterdam/Philadelphia: John Benjamins.

Alger, C. (2009). Secondary Teachers. Conceptual Metaphors of Teaching and Learning: Changes Over the Career Span. Teaching and Teacher Education, 25, 743-751.

Ben-Peretz, M., Mendelson, N. y Kron, F. W. (2003). How Teachers in Different Educational Contexts View Their Roles. Teaching and Teacher Education, 19(2), 277-290.

Block, D. (1992). Metaphors We Teach and Live By. Prospect, 7(3), 42-55.

Borg, S. (2003). Teacher Cognition in Language Teaching: a Review of Research on What Language Teachers Think, Know, Believe, and Do. The International Abstracting Journal for Language Teachers and Applied Linguists, 36(2), 81-109.

Bradley, K. y Van Brummelen, H. (2012). Metaphors We Teach By. How Metaphors Shape What We Do in Classrooms. Eugene, Oregon: Wipf and Stock.

Bullough, R. V. (1991). Exploring Personal Teaching Metaphors in Preservice Teacher Education. Journal of Teacher Education, 42(1), 43-51.

Caballero, R. (2006). Journey Metaphors in Foreign Language Teaching-Learning: Ways of Travelling/ 
Learning in Multimedia Environments. Mélanges Crapel, 28, 201-211.

Cameron, L. (2003). Metaphor in Educational Discourse. London: Continuum.

Cortazzi, M. y Jin, L. (1999). Bridges to Learning: Metaphors of Teaching, Learning and Language. In L. Cameron y G. Low, (eds.), Researching and Applying Metaphor (pp. 149-176). Cambridge University Press.

Dávila, M. A., Novais, R., Borrachero, A. B. y Mellado, L. (2017). Las metáforas sobre el profesor y el aprendizaje de estudiantes de Maestría de Brasil y España, Ciência \& Educação (Bauru), 23(1), 273-295.

Dalton, E. (2015). Metaphors We Learn By. Recuperado de https://www.academia.edu/12651157/ Metaphors_We_Learn_By

De Guerrero, M. C. y Villamil, O. S. (2002). Metaphorical Conceptualizations of ESL Teaching and Learning. Language Teaching Research 6(2), 95-120. Recuperado de: http://citeseerx.ist.psu.edu/viewdoc/download?d oi $=10.1 .1 .826 .8735 \&$ rep $=$ rep $1 \&$ type $=$ pdf

Dooley, C. (1998). Teaching as a Two-way Street: Discontinuities Among Metaphors, Images, and Classroom Realities. Journal of Teacher Education, 49(2), 97-107.

Jodelet, D. (1997). Représentation sociales: phénomènes, concept et théorie. En S. Moscovici, (dir.), Psychologie sociale. Paris: Presses Universitaires de France.

Kasoutas, M. y Malamitsa, K. (2009). Exploring Greek Teachers beliefs Using Metaphors. Australian Journal of Teacher Education, 34(2), 64-83.

Knowles, J. G. (1994). Metaphors as Windows on a Personal History: A Beginning Teachers' Experience. Teacher Education Quarterly, 21(1), 37-66.

Kövecses, Z. (2010 [2002]). Metaphor: A Practical Introduction, 2da. ed. Oxford University Press.

Kramsch, C. (2003). Metaphor and the Subjective Construction of Beliefs. En P. Kalajay y A. M. Barcelos (eds.), Beliefs about SLA: New Research Approaches (pp. 109-128). Dordrecht: Kluwer Academic Publishers.

Jin, L. y Cortazzi, M. (2017). Engineering the Soul: Construction and Sacrifice in the Teaching Profession. En A. Liljegren y M. Saks (eds.), Professions and Metaphors. Understanding Professions in Society. (pp. 130-146) London: Routledge, Taylor $\&$ Francis Group.
Lakoff, G. (1987). Women, Fire and Dangerous Things. What Categories Reveal about the Mind. University of Chicago Press.

Lakoff, G. y Johnson, M. (1980). Metaphors We Live By. Chicago: University of Chicago Press.

Langacker, R. W. (1987). Foundations of Cognitive Grammar. Vol. 1. Theoretical Prerequisites. Stanford University Press.

Leavy, A. M., McSorley, F. y Boté, L. (2007). An Examination of What Metaphor Construction Reveals About the Evolution of Preservice Teacher's Beliefs About Teaching and Learning. Teaching and Teacher Education, 23, 1217-1233.

Low, G. (2008). Metaphor and Education. En R. Gibbs, (ed.), The Cambridge Handbook of Metaphor and Thought (pp. 212-231). Cambridge University Press.

McManus, D. A. (2001). The Two Paradigms of Education and the Peer Review of Teaching, Journal of Geosience Education 49(5), 423-34.

Mahlios, M. y Maxson, M. (1998). Metaphors as Structures for Elementary and Secondary Preservice Teachers' thinking. International Journal of Educational Research, 29, 227-240.

Mellado, L., Luengo, M. R., Dela Montaña, J.L., Borrachero, A. B. y Bermejo, M. L. (2014). Las metáforas personales de estudiantes de Psicopedagogía sobre el profesor y el aprendizaje. Campo Abierto, 33(1), 153-170.

Mellado, L., De la Montaña, J. L., Luengo, M. R. y Bermejo, M. L. (2016). Evolución de los modelos docentes de futuros profesores de economía de secundaria, a través de la metáfora. Didáctica de las ciencias experimentales $y$ sociales, 30(1), 23-44.

Mellado, L., Sánchez Herrera, S., Vicente, F. y Bermejo, M. L. (2017). Las metáforas emocionales del aprendizaje de los alumnos visto por el futuro profesorado del máster de educación secundaria. International Journal of Developmental and Educational Psychology, 1(1), 149-158.

Moscovici, S. (1976 [1961]). La psychanalyse, son image et son public. Paris: Presses Universitaires de France.

Nikitina, L. y Furuoka, F. (2008). A Language Teacher is Like...: Examining Malaysian Students' Perceptions of Language Teachers Through Metaphor Analysis. Electronic Journal of Foreign Language Teaching, 5(2), 192/205. 
Northcote, M. (2009). Educational Beliefs of Higher Education Teachers and Students: Implications for Teacher Education. Australian Journal of Teacher Education, 34(3), 69-81.

Oxford, R. L., Tomlinson, S., Barcelos, A., Harrington, C., Lavine, R. Z., Saleh, A. y Longhini, A. (1998). Clashing Metaphors About Classroom Teachers: Toward a Systematic Typology for the Language Teaching Field. System, 26(1), 3-50.

Piquard, H. (1996). La notion d'enseignement-apprentissage: représentations d'une population d'enseignants à travers leur panel d'expressions métaphoriques. Mémoire de DEA, UFR Sciences du Langage, Université Nancy 2.

Pragglejaz Group (2007). MIP: A Method for Identifying Metaphorically Used Words in Discourse. Metaphor and Symbol, 22(1), 1-39.

Reddy, M. J. (1993 [1979]). The Conduit Metaphor: a Case of Frame Conflict in our Language About Language. In A. Ortony (ed.), Metaphor and Thought, second edition. (pp. 164-201). Cambridge University Press.

Riley, P. (1997). “BATS” and "BALLS”: Beliefs About Talk and Beliefs About Language Learning. Mélanges Pédagogiques, 23,125-153.

Saban, Ah. (2004). Prospective Classroom Teachers' Metaphorical Images of Selves and Comparing Them to Those They Have of Their Elementary and Cooperating Teachers. International Journal of Educational Development, 24(6), 617-635.

Saban, Ah. (2006). Functions of Metaphor in Teaching and Teacher Education: A review essay. Teaching Education, 17(4), 299-315.

Saban, Ah. (2010). Prospective Teachers' Metaphorical Conceptualizations of Learner. Teaching and Teacher Education,26, 290-305.

Saban, Ah., Kocbeker, B. N. y Saban, As. (2007). Prospective Teachers' Conceptions of Teaching and Learning Revealed Through Metaphor Analysis. Learning and Instruction, 17(2), 123-139.
Semino, E., Demjen, Z., Hardie, A., Payne, S. y Rayson, P. (2018). Metaphor, Cancer and the End of Life: A Corpus-based Study. London: Routledge.

Sullivan, K. (2017). Conceptual Metaphor. En B. Dancygier (ed.), The Cambridge Handbook of Cognitive Linguistics (pp. 385-406). Cambridge University Press.

Urdinez, M. (1 de marzo de 2014). ¿Docentes eran los de antes?, La Nación, Suplemento Comunidad, 8-11.

Thomas, L. y Beauchamp, C. (2011). Understanding New Teachers' Professional Identities Through Metaphor. Teaching and Teacher Education: An International Journal of Research and Studies, 27(4), 762-769.

Vygotsky, L. (1986 [1934]). Thought and Language. Translation Newly Revised and Edited by Alex Kozulin. MIT Press.

Wan, W., Low, G. y Li, M. (2011). From Students' and Teachers' Perspectives: Metaphor Analysis of Beliefs About EFL Teachers' Roles. System, 39(3), 403-415.

Wan, W. y Low, G. (2015). Introduction. En W. Wan y G. Low (eds). Elicited Metaphors Analysis in Educational Discourse (pp. 1-12). Amsterdam/Philadelphia: John Benjamins.

Wood, D., Bruner, J. S. y Ross, G. (1976). The Role of Tutoring in Problem Solving. Journal of Child Psychology \& Psychiatry and Allied Disciplines, 17, 89-100. Reproduce in J. S. Bruner (2006). In Search of Pedagogy. Volume 1. The Selected Works of Jerome S. Bruner. London and New York: Routledge, Taylor \& Francis Group.

Xiong, H., Li, L. y Qu, Y. (2015). Exploring EFL Teachers' Cognitive Models Through Metaphor Analysis. SAGE Open, October-December, 1-11. Retrieved from: http://journals.sagepub.com/doi/ abs/10.1177/2158244015608900

Zapata, G. y Lacorte, M. (2007). Pre-service and In-service Instructors' metaphorical Constructions of Second Language Teachers. Foreign Language Annals, 40(3), 521-534. 